\title{
Is Watching Television a Realistic Leisure Option for People with Dementia?
}

\author{
Margrét Gústafsdóttir \\ Faculty of Nursing, University of Iceland, Reykjavík, Iceland
}

\author{
Key Words \\ Social context · Contact · Watching television · Togetherness · Quality time
}

\begin{abstract}
Background: Watching television is a common leisure activity, not least among older people. However, watching television may become difficult when it is disturbed by symptoms of dementia. Method: A total of 284 questionnaires were handed out to relatives of people with dementia in Iceland, in the Memory Clinic of the University Hospital and in specialized units for people with dementia (6 day-care units and 8 units within nursing homes). The response rate was just below $58 \%$. Results: Watching television was shown to play a less important role in the course of the daily life of people with dementia as soon as the symptoms of the disease became evident, and it increasingly became less relevant. So, this previous leisure activity left an ever-growing void of time to fill. However, watching television may provide an important social context for contact and togetherness during the progress of the disease, as watching television with someone close to them was important for the individuals with dementia. Conclusion: It is not a viable option for people with dementia to watch television on their own, but they may enjoy watching television while sharing this activity with a person close to them. This may even provide quality time.

(C) 2015 S. Karger AG, Basel
\end{abstract}

\section{Introduction}

My interest in this topic came about while interviewing relatives of people with dementia [1], as watching television always happens to be mentioned in these interviews. Some relatives had even invested money in some special channels to find some way of occupying a person with dementia. But it became very clear during these interviews that it might be hard 
to find something that would keep the person with dementia occupied. I had also noticed in my earlier research in institutions that the television was very often left turned on both in communal places and in private rooms. So, I started to look for literature about watching television by people with dementia; unfortunately, there was not much to be found. It has been pointed out that 'watching television is an experience shared by the vast majority of children and adults. It is convenient, inexpensive, available and attractive' [2, p. 1]. Watching television has also been referred to as a very common cognitive activity [3]. However, it has been under attack as a sedentary leisure activity, and the increased 'risks associated with physical inactivity are well documented and include obesity, cardiovascular disease and type II diabetes' [4, p. 747]. Other sources also emphasize these consequences of watching television and its concomitant physical inactivity $[5,6]$.

Wang et al. [7, p. 482] suggest that 'leisure activity can be defined as the voluntary use of free time for activities outside the daily routine'. They further argue that 'it is one of the major components of a healthy lifestyle. After retirement leisure time constitutes a relatively larger part of the daily life, leisure time activities have emerged as the most important target for lifestyle changes among older adults because of the potentially beneficial effects on various health outcomes'. It has also been maintained that 'for the elderly satisfaction with leisure activities is one of the best predictors of overall life satisfaction' [8, p. 489].

It has been noticed that people aged over 65 watch more television than younger and middle-aged adults [9]. However, little is known about the habits of watching television by people with dementia, although it might be expected to be a part of everyday life for most people. However, behavioral symptoms of dementia are seen as an interfering factor in this group when performing any leisure activity [10-13]. Different means have been proposed for the creation of appropriate activities. It has been emphasized with regard to activities for people with dementia that 'skill-level-appropriate activities afford the opportunity for participation. Second activities are prescribed so they match the individual's style of interest as determined by their personality traits of extraversion and openness' [10, p. 327]. Apart from the skill level or interest, one has become accustomed to television sets being left switched on in public places such as waiting rooms or semi-public ones such as the lounges of most nursing homes. It appears that people with dementia hardly stay in one place watching television, except when somebody else is around who watches with them. However, if passivity is the overall characterizing symptom of dementia [11], the person may just continue to sit in front of the television set no matter what television program is on.

Caregivers of people with dementia may, however, attempt to occupy both passive and restless individuals with watching television, just to provide them with some sort of diversion or rest and so that they themselves have a little respite. Caregivers are often unsure how to occupy people with dementia, and they may see the television as the main resource to lean on for occupation or engagement. Unfortunately, this resource does not tend to work, especially since restlessness often seemed to be ingrained into the symptoms of dementia [12, 13]. Perhaps the lack of interest in the phenomenon of watching television by people with dementia may be attributed to the view that it is futile, in spite of 'accumulated evidence [that] shows that leisure activities have a positive impact on cognitive function and dementia' [7, p. 482].Watching television may not be an ideal activity for people with dementia, although, as was pointed out earlier, 'it is a convenient, inexpensive, available and attractive activity' [2, p. 1].

In Iceland, where the study was conducted, only a limited number of television channels are widely accessible. A single state-run television station, which includes a sports channel, is available everywhere, whereas other channels are subscription only.

It may be worth mentioning that state-run television and one of the subscription channels broadcast daily news at 18:30 and 19:00 h, respectively, every night. Most Icelanders are in the habit of watching one or both of them. 


\section{Methods}

A letter asking relatives to fill out a questionnaire and the questionnaire itself were developed with the help of two registered nurses (RNs) familiar with the care of people with dementia. Two sociologists specializing in survey methods also helped, in particular with the drawing-up of the questionnaire. The questionnaire was designed in a very simple manner and with the aim of simply finding out whether people with dementia watched television and the effect the disease had upon their watching. The questionnaire comprised 13 questions, of which the first 3 asked for demographic data, i.e. age and gender as well as how much time had passed since the symptoms of the illness first manifested themselves. Questions 4, 5, 6, 7 and 8 asked about the habits of watching television before and after the diagnosis of the illness. Question 4 asked in particular about changes in habits of watching television at different times during the course of the disease (when the symptoms became evident, after the diagnosis and at the time of answering the questionnaire). Question 8 asked about how the content and the structure of television programs affected the watching patterns, and questions 10,11, 12 and 13 inquired about the circumstances, such as how the place and time affected the watching and what impact being able to share the experience of watching television with another person or persons had on the watching. There were no questions about behavioral symptoms other than the behavior that was directly related to watching television.

The questionnaire was then distributed to the various locations, after the National Bioethics Committee had approved the study. The committee had initially queried the wording of the letter, because it found it unclear. The letter was reworded to clarify that the questionnaire had to be answered by relatives, although it was stated that the person with dementia might wish to do this himself/herself if he/she were able. It was also emphasized that the relatives were welcome to ask staff for help in answering the questionnaire, should the person with dementia live in a nursing home. After revision of the letter, approval for the study was granted.

Two pilot studies, one in a day-care unit (involving a husband) and another in a nursing home unit (involving a daughter), turned out favorably, but it transpired that it would be preferable, as emphasized in the final version of the letter to the relatives, if they consulted staff in the nursing homes about any time - however little - the person with dementia spent watching television. Neither the National Bioethics Committee nor the relatives made any comments about the questionnaire.

The aim and approach of the study were explained during meetings with various RNs at the Memory Clinic of the University Hospital and in the various units in the 8 nursing homes. A single general meeting with the managers of the 6 day-care units served the same purpose. During this meeting each manager received an information pack containing individual introductory letters to relatives and copies of the questionnaire along with stamped addressed envelopes.

It was clear from the outset that the managers of the day-care units might have some problems in reaching the relatives - but most of them succeeded quite resourcefully. The managers spoke to many relatives on the phone to ask whether they were willing to participate in the research project and whether they could send them a letter and a questionnaire with a stamped addressed envelope. In many cases the managers arranged to have the papers delivered by the driver who took the elderly person home at the end of the day.

The RNs at the Memory Clinic talked to the relatives about their possible participation during their second visit to the unit after a diagnosis of dementia had been confirmed. RNs in the specialized units for patients with dementia in nursing homes generally handed out the letter and the questionnaire personally to the relatives and encouraged them to ask staff for help in filling it in. Both in the day-care units and in the nursing homes, RNs used their own judgment to determine whether there was any point in suggesting participation to a relative. 
Table 1. Number of answers by the age of the people with dementia in 2011
Gústafsdóttir: Is Watching Television a Realistic Leisure Option for People with Dementia?

\begin{tabular}{ll}
\hline Number of answers & Age \\
\hline 29 & $99-90$ years (born 1912- 1921) \\
73 & $89-80$ years (born 1922-1930) \\
41 & $79-70$ years (born 1931-1940) \\
8 & $69-60$ years (born 1941-1952) \\
1 & $59-50$ years (born 1953-1962) \\
\hline
\end{tabular}

Total number of relevant answers: 152 (64 males and 89 females). The answers of individuals aged between 50 and 69 years were not considered.
Table 2. Time since diagnosis and number of individuals with dementia

\begin{tabular}{|c|c|}
\hline Years since diagnosis & Individuals with dementia \\
\hline $1-2$ years (12-23 months) & 5 \\
\hline $2-4$ years (24-47 months) & 28 \\
\hline $4-6$ years ( $48-71$ months) & 38 \\
\hline $6-8$ years ( $72-95$ months) & 27 \\
\hline $8-10$ years (96-119 months) & 11 \\
\hline $10-12$ years ( $120-143$ months) & 12 \\
\hline $12-14$ years (144-167 months) & 22 \\
\hline $14-16$ years (168-191 months) & 5 \\
\hline $16-18$ years (192-215 months) & 1 \\
\hline $18-20$ years (216-239 months) & 1 \\
\hline $20-22$ years ( $240-263$ months) & 1 \\
\hline $35+$ years (>420 months) & 1 \\
\hline Total & 152 \\
\hline
\end{tabular}

The questionnaire was only intended to obtain descriptive statistics, and this paper will attempt to give a picture of the habits of watching television among people with dementia. It should be noted that a very large number of letters and questionnaires were distributed to the units in order to ensure that plenty would be available for the RNs to hand out or send to relatives. Also, it should be noted that most units developed a system for recording the names of the persons who had been spoken to and to whom they had handed or sent the letter, the questionnaire and the envelope.

\section{Results}

The results of this study were descriptive as expected. Tables 1 and 2 show that the sample reflects the accepted picture of dementia quite well. Most of the individuals with dementia were very old, i.e. in their 80 s or 90 s (102), while 41 were in their 70 s; the other few younger individuals were not considered (table 1 ). Table 2 shows that the sample included people with a varying duration of illness as well as the long road that people usually face after being diagnosed with dementia.

Watching television had played a large role in everyday life of most of the individuals (70\%) before the illness. After the symptoms of dementia had become evident, watching television played a diminishing role in their everyday life (72\%). The situation deteriorated after the diag- 
Gústafsdóttir: Is Watching Television a Realistic Leisure Option for People with Dementia?

nosis of dementia, as television played an even smaller role in the life of $47 \%$ of the individuals with dementia and had little importance for most. In fact, watching television had little significance in everyday life of most of the individuals (74\%) at their present stage of the illness, regardless of the stage of their disease or of how much time had passed since their diagnosis.

Watching television had been a routine part of everyday life in $84.8 \%$ of the individuals with dementia before the symptoms of the illness became evident. Most of them had spent from 1 to 4-6 h watching television, mainly in the late afternoon and in the evening. There was not much difference in the pattern of habits of watching television between workdays and days off.

At the present time (at the time of the survey) watching television was no longer a routine part of everyday life of most of the people with dementia. More of them spent very little time watching television $(\sim 1 \mathrm{~h})$ compared to before the illness. The pattern of their habits of watching television was the same, mostly during the late afternoon and evening. All the same, a few people with dementia spent a considerable amount of time watching television, i.e. $2-5 \mathrm{~h}$.

Indeed, the majority of the individuals with dementia watched the news or some newsrelated program in the evening, and more than half watched Icelandic-made news documentaries. Some watched educational programs of all kinds. Very few watched foreign-language news documentaries. Watching entertaining programs scored quite highly among them (62\%), as did nature documentaries (55\%). Films rated relatively highly, especially musicals (38\%) and comedies (31\%). Romances (14\%), Technicolor films (15\%) and thrillers (14\%) rated less highly. Relatively few of the respondents mentioned sports, but those that did referred to specific sports programs (41\%), especially various ball games.

Notably, neither the plot (23.5\%) nor the length (23.5\%) of the film had much influence on their stamina for watching, while familiarity with the content $(63.9 \%)$ influenced stamina considerably, as did old interests (35.3\%). The persons appearing on the screen influenced some $(31.9 \%)$ - a few felt that attractive individuals had a positive effect. Differences were seen in the significance of circumstances: while the company of others mattered the most (37.9\%), other circumstances that mattered were: time of day $(26.8 \%)$, always when television was turned on $(17 \%)$, special refuge $(16.3 \%)$ or a particular chair or bed $(20.3 \%)$. The closeness of others seemed to affect the habits of watching television: sitting in a group with others mattered (47.7\%), as did having someone around (36\%), but what mattered most to individuals was sitting with someone close to them (75.6\%); holding hands was not an important factor $(22.1 \%)$.

\section{Discussion}

Watching television was shown to play a less important role during the course of the daily life of people with dementia as soon as the symptoms of the disease became evident, and it increasingly became less relevant. So, this previous leisure activity left an ever-growing void of time to fill. It has been stated that: 'Recreational activities are used to fill unoccupied time and may manage behavioral symptoms, but results of efficacy studies were modest' [13, p. 220].

This research may evoke more questions than answers about watching television by people with dementia. It appears that the deteriorating cognitive processes of dementia affect the ability of the individual with dementia to watch television. The study concludes very clearly that the ability to watch television disappears quite early in the disease process of dementia. The question may be asked whether the habits of watching television and sharing this activity may indeed be a more important factor than the time that had elapsed since the diagnosis of the disease. It is, however, hard to say whether people with dementia 
have difficulties focusing their attention on the screen or whether what they see on the screen appears meaningless to them, so that they do not comprehend what is going on. Little is known about the way in which cognitive processes affect watching television or about how the meaning of the content on the screen affects cognitive processes. However, memory and interest seem to provide some familiarity with people and places $[14,16]$. Hence, watching television may serve as a form of reminiscence therapy. One may ask whether watching television may be cognitively stimulating. It is also hard to tell whether the company of others helps the person with dementia to focus on the screen, whether it helps him/her to relate better to the content of the screen or whether the significant factor is simply the feeling of sharing an activity with somebody. Whatever the reason, it is clear that people with dementia enjoy the company of others when they watch television; this appears to create quality time for the person, although the quality of life of a person with dementia is hard to evaluate [14, $15,17]$. However, Cooper et al. [15] point out that quality of life may be conceptually different in mild, moderate and severe dementia. At the same time, however, it may be utterly futile simply to switch the television on, place the person with dementia in front of the screen and then disappear.

\section{Limitations}

The sample of people with dementia in the focus of this research may seem rather broad and diverse, as it includes so many institutions where they receive treatment. However, as pointed out by Marshall and Hutchingson [8], 'patients present with different clinical pictures at different times during the course of their disease; certainty about staging or profiling is difficult at best' [8, p. 490]. As shown in table 2, the time that had elapsed since the diagnosis of dementia varied considerably; almost all the people making up the sample were diagnosed according to the same criteria at the Memory Clinic of the University Hospital. Marshall and Hutchingson [8] emphasize that researchers should select patients diagnosed by similar criteria in order to obtain a homogeneous sample. At the same time, one might expect the people attending the Memory Clinic to have the least advanced symptoms of dementia illness, the people in nursing homes to have the most advanced symptoms, and the people in the day-care units to be somewhere in between. In view of this, it might have been preferable to study each group separately. Fewer relatives responded to the latter part of the questionnaire; it is possible that they were deterred by question 7, which asked whether watching television was now a part of everyday life of the person with dementia. At any rate, only 119 out of the 152 respondents answered questions 9 and 10 about the specific content of the television programs watched. Unfortunately, even fewer of the respondents ( 97 respondents) answered the questions about the circumstances that were significant. An even smaller proportion of the respondents (86 respondents) answered the question about the importance of being with others while watching television.

\section{Conclusion}

Watching television is not a particularly good leisure activity for people with dementia, unless the content and/or circumstances are tailored to each and every individual. Individual assessment has been shown to be crucial in all treatments for people with dementia [18], and the same appears to be true when choosing leisure activities for a person with dementia - be it watching television, walking, cooking or something else which the person with dementia can share with someone close to him/her. Sharing an activity may be the crucial factor. 


\section{Disclosure Statement}

There are no conflicts of interest.

\section{Acknowledgements}

The author is very grateful to all the relatives that responded to the letters and returned the questionnaires, and she also expresses her heartfelt thanks to all the RNs who distributed the information packs and spoke to the relatives on the researcher's behalf. Two RNs, Gudrun Karlsdottir, manager of the Memory Clinic, and Olina K. Jonsdottir, a former Staff Nurse in a dementia unit and the present director of one of the day-care centers, provided valuable advice about the content and wording of the letter and the questionnaire. Two social scientists, Heidur Hrund Jonsdottir and Ingibjorg Lilja Omarsdóttir, gave advice about the design of the questionnaire. Anny Lara Emilsdottir, RN, an Assistant Teacher of the Gerontological Nursing Course, managed all the questionnaires and entered the responses into a statistical tool (SPSS), and social scientist Ingibjorg Lilja managed and delineated the output of the statistical work. Finally, Anna Yates carried out valuable editing of this paper.

\section{References}

1 Gústafsdóttir M: The family's experience of sharing the care of a person with dementia with the services in specialized day-care units. Dement Geriatr Cogn Disord Extra 2014;4:344-354.

2 Medline Online, p. 1. http://www.nlm.nih.gov/medlineplus/ency/article/002329.htm (accessed September 17, 2013).

-3 Liberati G, Raffone A, Olivetti Belardinelli M: Cognitive reserve and its implication for rehabilitation and Alzheimer's disease. Cogn Process 2012;13:1-12.

4 Burton NW, Khan A, Brown WJ, Turell G: The sedentary leisure and physical activity in middle age adults. Br J Sports Med 2012;46:747-752.

-5 Kronenberg F, Pereira MA, Schmitz MK, Arnett DK, Evenson KR, Crapo RO, Jensen RL, Burke GL, Sholinsky P, Ellison RC, Hunt SC: Influence of leisure time physical activity and television watching on atherosclerosis risk factors in the NHLBI Family Heart Study. Atherosclerosis 2000;153:433-443.

6 Hu FB, Li TY, Colditz GA, Willett WC, Manson JE: Television watching and other sedentary behaviors in relation to risk of obesity and type 2 diabetes mellitus in women. JAMA 2003;289:1785-1791.

7 Wang H-X, Xu W, Pei J-J: Leisure activities, cognition and dementia. Biochim Biophys Acta 2012;1822:482-491.

-8 Marshall MJ, Hutchingson SA: A critique of research on the use of activities with persons with Alzheimer's disease: a systematic literature review. J Adv Nurs 2001;35:488-496.

$\checkmark 9$ Depp CA, Schkade DA, Thompson WK, Jeste DV: Age, affective experience and television use. Am J Prev Med 2010;39:173-178.

10 Kolonowski A, Buettner L, Moeller J: Treatment fidelity plan to an activity intervention designed for persons with dementia. Am J Alzheimers Dis Other Demen 2006;21:326-332.

11 Kolonowski A, Buettner L: Prescribing activities that engage passive residents. J Gerontol Nurs 2008;34:13-18.

12 Neistein S, Siegal AP: Agitation, wandering, pacing, restlessness and repetitive mannerisms. Int Psychogeriatr 1996;8(suppl 3):399-402.

13 Kolonowski A, Litaker M, Buettner L: Efficacy of theory-based activities for behavioral symptoms of dementia. J Nurs Res 2005;54:219-228.

14 Brooker D, Duce L: Wellbeing and activity in dementia: a comparison of group reminiscence therapy, structured goal-directed group activity and unstructured time. Aging Ment Health 2000;4:354-358.

15 Cooper C, Mukadam N, Katona C, Lyketsos CG, Ames D, Rabins P, Engedal K, de Mendonça Lima C, Blazer D, Teri L, Brodaty H, Livingston G: Systematic review of the effectiveness of non-pharmacological interventions to improve quality of life of people with dementia. Int Psychogeriatr 2012;24:856-870.

16 Douglas S, James I, Ballard C: Non-pharmacological interventions in dementia. Adv Psychiatr Treat 2004;10: 171-177.

17 Bruvik FK, Ulstein ID, Ranhof AH, Engedal K: The quality of life of people with dementia and their family carers. Dement Geriatr Cogn Disord 2012;34:7-14.

18 Ulstein ID, Sandvik L, Wyller TB, Engedal K: A one-year randomized controlled psychosocial intervention study among family carers of dementia patients - effects on patients and carers. Dement Geriatr Cogn Disord 2007; 24:469-475. 